\title{
Changes Beyond Limits: Proofreading in an American University
}

\author{
Ahmad I Alhojailan \\ Department of English Language and Translation \\ College of Arabic Language and Social Studies, Qassim University, Saudi Arabia \\ E-mail: a.alhojailan@qu.edu.sa
}

Received: August 16, 2019 Accepted: September 9, 2019 Published: October 16, 2019

doi:10.5296/ijl.v11i5.15280

URL: https://doi.org/10.5296/ijl.v11i5.15280

\begin{abstract}
Students are usually asked to submit term papers, reports, research proposals, dissertations, theses, etc. for assessment purposes. Unfortunately, not all students are able to write at the level that their professors expect. Therefore, students are encouraged by their professors to have their papers carefully proofread before submission. This study investigates the beliefs, practices, and experiences of proofreaders who proofread students' writing, along with different issues related to proofreading. Semi-structured interviews were conducted with two proofreaders studying for their Ph.D. in the English Department in a university in the American Southwest. The results show that a misunderstanding of the role of a proofreader exists between proofreaders and student writers and among proofreaders themselves. My findings also show that proofreading is used only for academic survival. I highlight how the educational system and the proofreaders' qualifications have affected the description of proofreading. The results emphasize the need for implementing regulations for proofreading services to guarantee that they are standardized and administered consistently to avoid misrepresentation of students' true writing abilities, and to maintain a good reputation for universities with respect to their graduates' writing skills.
\end{abstract}

Keywords: Proofreading, Academic writing, Ethics, Practices, Writing, Student

\section{Introduction}

An increasing number of students, native (NS) and nonnative speakers (NNS) of English, are enrolling in universities where the instructional language and most students' native language is English (Institute of International Education, 2014). According to Flowerdew (1999), most ESL/EFL students who complete their studies in universities in English-speaking countries and English-language universities in non-English speaking countries (e.g., the United States 
of America, the United Kingdom, Japan, and Canada) encounter difficulties in academic writing.

Reid and Kroll (1995) points out that writing is a significant tool for social activities. For example, if we consider the anticipated behavior between the student-writer and the teacher-reader, we can classify this kind of behavior as not to persuade, inform, or entertain the teacher but to deliver the assignments commensurate with the teacher's expectations (Belanoff, 1991; Horowitz, 1991; Popken, 1989). Therefore, it can be said, in this domain, that academic writing is a form of testing performed by students and supervised by teachers.

Students are usually asked to submit essays, term papers, reports, case studies, research proposals, dissertations, and theses for assessment purposes. Unfortunately, not all students are able to write at the level that their professors expect. Moreover, many studies have found that the errors in the students' assignments may affect their grades, whether positively or negatively (Harwood, 2018). Therefore, students are encouraged by their professors to carefully proofread their papers before submission. However, many students might lack the required experience, training, or qualifications that enable them to proofread their research papers. As a result, some of those students, especially NNS, tend to seek the help of a proofreader to enhance the quality of their work before submitting it (Scurr, 2006). The importance of this study lies in its ability to help universities establish more consistent criteria for proofreading services, which in turn will produce better writers upon graduation.

\section{Literature Review}

Different researchers have tackled the term "proofreader" and pointed out that there is a dispute over the terminology most suitable to define a person providing proofreading services. Burrough-Boenisch (2013) and Harwood, Austin, and Macaulay (2009), for example, listed several terms used to refer to the providers of such services (e.g., copy editor, language corrector, error corrector, and proofreader). In recent decades, there has been an increasing interest in proofreading, which researchers have tackled from different angles. Reid (1994), for example, explored the reason why NNS writers ask for proofreading services, and she claimed that they might lack the knowledge of how to meet a Western audience's expectations. Moreover, Hiep (2011) examined the influence of proofreaders on translated texts. In addition, Bisaillon (2007), Burrough-Boenisch (2003a), Lillis and Curry (2006), and Mauranen (1997) investigated how proofreaders assist nonnative academics with publishing their writing in English-language journals. Furthermore, Harwood et al.'s study (2009) focused on the beliefs and practices of those who proofread nonnative students' writing. Additionally, Lines (2016) explored the qualifications of proofreaders.

Proofreading providers (people, centers, universities) and receivers do not have fixed policies and expectations regarding the outcomes of proofreading process. Turner (2010), for example, points out that there are "inconsistencies in the use of terms such as 'correcting', 'checking', and 'proofreading', what they are applied to, and what is involved in the work undertaken" (p. 39). Research shows considerable variety; the procedures of the proofreaders range from the correction of surface mistakes to the suggestion of important structural modifications. For example, Harwood et al. (2009) interviewed 16 proofreaders in a British university. The 
proofreaders revealed that they comment on the errors rather than correcting them. Lines (2016), on the contrary, found out that the proofreaders in her study in Australia made major changes at the level of content and argumentation. Additionally, there were 11 proofreaders in a Japanese university with differing academic writing knowledge in Rebuck's study (2014). They were given the same 300-word extracts from 15 Master's theses. Unfortunately, according to Rebuck, some of the proofreaders replaced some of the disciplinary terms and that led to meanings complete different from those intended by the writers. Moreover, Harwood (2018) pointed out that the number of interventions made by the proofreaders who were in England at the time of his study differed greatly, although they were given the same essay to proofread. Additionally, Kruger and Bevan-Dye (2010) explored the beliefs and practices of proofreaders of student writing in South Africa. It was found that a disagreement exists among proofreaders when it comes to the types of changes acceptable to make to the content of a manuscript.

Several studies in the literature explored the beliefs, practices, and experiences of proofreaders in different countries (e.g., England, Japan, Australia, and South Africa), most of whom consider proofreading their main job or a part-time job in addition to their full-time one. The current study aims to explore the beliefs, practices, and experiences of proofreaders who are graduate students in an American university. Those proofreaders proofread only for students. The study also aims to explore the respondents' qualifications that made them think they are eligible to be proofreaders and what they consider to be qualifications (i.e., courses and experiences) of good proofreaders. For example, what kind of knowledge, experience, academic background, training, and experience in academic writing should proofreaders have? Additionally, the study will explore the proofreaders' (un)willingness to make changes to some parts they are proofreading and the kinds of errors they are (un)willing to correct. In this part, I will touch on the ethical issues that proofreaders encounter while they are proofreading. Therefore, this paper seeks to address the following research questions:

1-What are the qualifications of a good proofreader?

2-What are the ethical issues encountered by a proofreader?

3-What types of interventions is a proofreader willing to make?

\section{Methodology}

\subsection{Instrument}

Rubin and Rubin (1995) mentioned that qualitative interviews enable researchers to ascertain others' perceptions of their environments. Furthermore, the researcher can comprehend experiences even if he or she was not involved in those experiences. A semi-structured qualitative interview will provide an opportunity to introduce the topic to the interviewees and guide the discussion to help answer the research questions. The result of such method is more reliable as detailed information are provided, which will provide a strong basis for the researcher's study (Miles \& Huberman, 1994).

Some of the questions in the interview were borrowed from the study conducted by Harwood et al. (2009) and some were generated by the researcher himself, and the interviewees were 
given space to express their opinions freely. The questions borrowed from Harwood et al.'s study were used in this study because they provide answers for some of the research questions (for example, “do you ever have doubts as to what kind of help you should give?"). On the other hand, there were some questions that were prepared by the researcher to serve the purpose of the study (for example, "how do you evaluate your success in proofreading?"). The questions for the interview can be found in Appendix 1.

Two interviews were conducted. They were tape-recorded and varied in length from 45 minutes to one hour. The interviews were informal and open-ended and conversational. The interview questions were designed to reveal answers for the research questions. However, the semi-structured nature of the interview gave the researcher discretion to add questions as required. Moreover, the interviewees were asked about related topics that arose during the interviews.

\subsection{Participants}

The proofreaders in this study are two male Ph.D. students in the Department of English at a university in the American Southwest, one of whom is a native speaker of English and the other a nonnative speaker. They proofread as a part-time job. They each hold a graduate degree in English and have experience writing in various academic genres. In addition, they are graduate teaching assistants and have teaching backgrounds in different courses (e.g., Grammar, Composition 1, and Composition 2) for both native and nonnative speakers of English. Their names are listed in the department's website as proofreading service providers. Although there were five names listed in the websites, only two of them agreed to be interviewed.

\subsection{Data Analysis}

Marchall and Rossman (1999) stated that coding is a very important first step in data analysis. Rubin and Rubin (1995, p. 207) referred to coding as "[T]he process of grouping the interviewees' responses into categories that bring together the similar ideas, concepts, or themes you have to discover or [reveal] steps or stages in a process." This study's interview-based design allowed for initial codes to be recognized. an example of the coding process in Table 1.

Table 1. An example of the coding process

\begin{tabular}{ll}
\hline \multicolumn{1}{c}{ CODE } & \multicolumn{1}{c}{ EXAMPLE } \\
\hline Fee & $\begin{array}{l}\text { \$15 for half an hour or \$25 for each hour if it took more } \\
\text { than half an hour. }\end{array}$ \\
\hline Academic background & $\begin{array}{l}\text { I am a PhD student, and my Bachelor's and Master's } \\
\text { degrees are in English and literature. }\end{array}$ \\
\hline Reasons for proofreading & $\begin{array}{l}\text { Money and friends. Also, I am interested in students' } \\
\text { writing, so this is going to help me. }\end{array}$ \\
\hline Terms describing proofreading & $\begin{array}{l}\text { Proofreading [is] more focused...and students bring } \\
\text { papers that are almost done. }\end{array}$ \\
\hline
\end{tabular}




\section{$\Lambda$ Macrothink}

\section{Findings}

\subsection{Proofreaders' Profiles}

Table 2 provides an overview of the informants, Allen (a pseudonym), the native speaker of English, and George (also a pseudonym), the nonnative speaker of English, regarding the skills and experience a proofreader should possess, their own academic backgrounds and training, and their experiences in academic writing.

Table 2. The proofreaders' profiles

\begin{tabular}{|c|c|c|}
\hline CATEGORY & PARTICIPANTS & QUALIFICATIONS \\
\hline \multirow[t]{2}{*}{$\begin{array}{l}\text { Proofreader's } \\
\text { skills }\end{array}$} & Allen & $\begin{array}{l}\text { S/he should be aware of the grammar and } \\
\text { punctuation rules and should be an excellent typist } \\
\text { (to know why the students made those mistakes). }\end{array}$ \\
\hline & George & S/he should possess grammatical knowledge \\
\hline \multirow[t]{2}{*}{$\begin{array}{l}\text { Proofreader's } \\
\text { experience }\end{array}$} & Allen & $\begin{array}{l}\text { Proofreading experience and some courses if } \\
\text { possible. }\end{array}$ \\
\hline & George & Proofreading experience. \\
\hline \multirow{2}{*}{$\begin{array}{l}\text { Personal } \\
\text { academic } \\
\text { background }\end{array}$} & Allen & $\begin{array}{l}\text { Bachelor's and Master's degrees in English and } \\
\text { creative writing. Moreover, I am a Ph.D. student in } \\
\text { the English department. }\end{array}$ \\
\hline & George & $\begin{array}{l}\text { Bachelor's and Master's degrees in English and } \\
\text { literature. Moreover, I am a Ph.D. student in the } \\
\text { English department. }\end{array}$ \\
\hline \multirow[t]{2}{*}{ Training } & Allen & $\begin{array}{l}\text { Taking some courses in proofreading would be } \\
\text { helpful. }\end{array}$ \\
\hline & George & Taking some courses in writing and grammar. \\
\hline \multirow{2}{*}{$\begin{array}{l}\text { Personal } \\
\text { experience in } \\
\text { academic } \\
\text { writing }\end{array}$} & Allen & $\begin{array}{l}\text { I wrote my thesis, various term papers, and } \\
\text { abstracts for conferences. }\end{array}$ \\
\hline & George & I wrote my thesis and many research papers. \\
\hline
\end{tabular}

As shown in Table 2, the respondents hold a graduate degree. Moreover, Allen and George are studying English and either creative writing or literature, respectively. Both respondents revealed that they have experience in academic writing. Regarding the skills that a proofreader should have, Allen stated that a proofreader should be aware of the grammar and punctuation rules and should be an excellent typist in order to know why the students made those spelling mistakes. The nonnative interviewee emphasized only on having grammatical knowledge. Furthermore, they identified courses in proofreading, writing, and grammar as ideal training for proofreaders. 


\subsection{Terminology to Describe Proofreading}

When it came to the term used by the interviewees to describe their job, both of them mentioned that the term "proofreader" represents their services accurately. Allen, for example, stated that he would call the service he provides "proofreading" because:

It is more focused...students bring papers that are almost done... I read them and check [for] mistakes at the sentence level. (Allen, Interview Transcript, p. 3)

However, both informants pointed out that their students use different terms to describe the services provided by the proofreaders, including both "proofreading" and "tutoring."

\subsection{Different Types of Intervention}

Allen and George mentioned that, during their first meeting with the students, they ask them about their expectations and what they (the students) want them (the proofreaders) to do. Moreover, Allen added that he asks students whether they want him to look at a particular section or chapter. George, on the other hand, is more serious and direct with his customers. He says, for example:

I tell them that I will not correct the content... I will not rephrase the wrong sentences... But I will underline them... Do not expect me to rewrite your paper for you. (George, Interview Transcript, p. 7)

Unlike George who pointed out that his intervention will be only on grammar and punctuation rules, Allen revealed that if he read a fact that was not true, he would ask the student to confirm its accuracy. Moreover, the respondents agreed that they have doubts about the type of help that they should provide, especially when it came to the content of the texts they are proofreading. George, for example, clarified that he would alert the student to the grammatical error if he thought that the meaning of a sentence would be altered by correcting that error.

Allen revealed that he would ask students to ask their professors about which style they should follow if he (Allen) noticed that there were several errors in citations. Additionally, the interviewees agreed that they would correct the page numbers, spellings, words (as long as the meaning of the sentence(s) does not change), title chapters, and page layout. Moreover, they agreed on not changing the table of contents.

The interviewees stressed in the interviews that they tend to reject proofreading topics that are not familiar to them. Allen, for example, mentioned that he wants to be fair with the students and ensure that they get their money's worth by providing the type of service they expect from him. In addition, the NNS students, according to both respondents, usually ask for grammar to be checked. On the other hand, the NS students ask them to focus on the content of their papers.

\subsection{Dealing With Errors}

The proofreaders in the current study reported that they would underline the error and correct it. If correcting an error would risk changing the meaning, the error would only be underlined 
and later discussed with the student. In addition, Allen mentioned that he would not correct all the errors under the following two situations:

1- If there are too many errors.

2- If the student has asked him to focus on one area (e.g., grammar and not spelling).

George, on the other hand, pointed out that he would correct every error he found in the students' texts.

\subsection{Follow-up}

The interviewees mentioned that they would meet their students face to face for the first time before beginning the proofreading process to discuss several issues with them (e.g., students' expectations, fees, etc.). However, unlike George, who said that the first meeting is enough, Allen mentioned that he prefers to also have a final meeting to explain to the students the changes he made in the texts.

Both respondents revealed that they usually do not usually have a follow-up because it is difficult to make such a request of a student. However, Allen mentioned that he would not ask a student to bring a copy of the instructor's feedback unless the student chose to do so. According to Allen, only one student came with his professor's feedback and asked in which sphere they (Allen and the student) had failed in meeting the professor's expectation.

Similarly, George indicated that he would not ask students to provide him with the instructor's feedback. However, he said he would do so with his friends in order to ascertain the expectations of the professors. Additionally, both respondents mentioned that being asked by the same student to proofread another term paper is considered a sign that they (the proofreaders) did well in proofreading the previous term paper.

\section{Discussion}

\subsection{Misunderstanding the Role of a Proofreader}

Unlike the proofreaders in Harwood et al.'s study (2009) who mentioned that they tend to comment on the errors rather than correcting them, the proofreaders in the current study reported that they would underline the error and correct it for the student. When George was asked about the reason for doing so, he said that the student paid for that kind of service. Combining both commenting and correcting, according to Bush and Henderson (2003) and D'Aloisio (2006), of course, will help the students become better writers and editors, which will help them have a successful career path.

Different from the proofreaders in Lines' (2016) and Harwood's (2018) studies, who mentioned that they were willing to make major changes at the level of content and argumentation, both respondents said that they focus only on sentence-level revisions and grammatical and lexical mistakes rather than arguments and content (despite the reported fact that some students asked them to do so, directly and indirectly). Despite their tendency to focus mainly on the students' texts that are written in their (the interviewees') field of study, allowing them to add valuable content and arguments to the students' texts, the respondents 
seem to acknowledge the ethical concerns that consistently occur during the proofreading process by refusing to risk exposure to ethical liability.

Such differences in dealing with errors show that there continues to exist a disagreement concerning the proofreader's role between the proofreader and students and among proofreaders themselves. Such a varied understanding of the role of the proofreader, unfortunately, could lead to a misrepresentation of students' true writing abilities.

\subsection{Proofreading is Only for Academic Survival}

Some of the findings of the current study are not consistent with those of previous ones.

Flowerdew and Wang (2016) and Luo and Hyland (2016) mentioned that the proofreaders in their studies contact the writers in order to resolve some of the difficulties in their texts. The respondents in the current study, however, pointed out that they rarely communicate with their clients during and after the proofreading process. Allen indicated that students do not want to learn the changes he made, which, unfortunately, will not make them better writers. The second interviewee, George, confirmed this point. He said that students want to be spoon-fed and that they are not interested in learning their mistakes. Such behavior from students, eventually, will produce better writing, not better writers.

\subsection{Factors Affecting the Description of Proofreading}

\subsubsection{The Effect of the Educational System}

Not many terms were listed by the respondents or by their students to refer to proofreading services, which could be due to the existence of the writing centers in the American universities (a free service where students are provided with support at all stages of the writing process). The respondents pointed out that they and their students mostly use the term "proofreading"; however, sometimes the students use the term "tutoring." A possible reason for using this term could be that it was commonly used by students in their high schools, wherein they wrote the assignments and most of the work was done by their teachers.

\subsubsection{The Effect of Qualifications}

Burrough-Boenisch (2003b) claims that good proofreaders should have knowledge of conventions of scientific English and perfect command of grammar. The informants in the current study meet those criteria; both have a graduate degree in English, wrote theses and research papers, and taught grammar and composition courses at the undergraduate level.

In the study conducted by Harwood et al. (2009), many terms were used (e.g., "proofreading," "text improvement," "text editing," "writing tutorial," "error correction," and "language correction"). Having different terms might be attributed to the fact that many proofreaders are not qualified (Lines, 2016), which could mean that proofreading service providers are using this practice to attract more students for financial gain. This explains why one of the proofreaders in Harwood's study (2018), who received proofreading training, made 472 emendations, whereas the other proofreader, who did not receive proofreading training, made only 113 emendations to the same essay (both of them have been providing proofreading services for more than five years). 


\section{Conclusion and Implications}

The aim of this study is to explore the beliefs, practices, and experiences of student writing proofreaders. Semi-structured interviews were conducted with two proofreaders in an American Southwest university who were simultaneously enrolled in doctoral programs in the English Department. The findings indicate that, between proofreaders and student writers and among proofreaders themselves, there is a misunderstanding of the role of a proofreader. In addition, it was found that proofreading is only used for academic survival. Finally, I outlined how the definition of proofreading was influenced by the educational system and the proofreaders' qualifications.

If universities want to maintain their reputations, they are encouraged to set guidelines to be followed by those allowed to advertise their proofreading services on the universities' websites and campuses. Additionally, students should be taught what is and is not allowed if they want to solicit the help of a proofreader for their papers. Students should know that not following these rules could negatively affect their future.

Since some proofreaders' practices demonstrated in the current and previous studies might not reflect the students' true writing abilities, which might compromise their learning and, in turn, their future success, this study joins other calls (e.g., Salter-Dvorak, 2019) for specific guidelines regarding the criteria for proofreading that include the student, tutor, and the proofreader.

\section{References}

Belanoff, P. (1991). The myth of assessment. Journal of Basic Writing, 10, 54 - 66.

Bisaillon, J. (2007). Professional editing strategies used by six editors. Written Communication, 24, 295-322. https://doi.org/10.1177/0741088307305977

Burrough-Boenisch, J. (2003a). Shapers of published NNS research articles. Journal of Second Language Writing, 12, 223-243. https://doi.org/10.1016/S1060-3743(03)00037-7

Burrough-Boenisch, J. (2003b). Editing texts by non-native speakers of English. In H. Maisonneuve, P. H. Enckell, A. Polderman, R. Thapa, \& M. Johnson-Vekony (Eds.), Science Editors' Handbook (Sect. 1-2.4, pp. 1-4). Guildford, UK: European Association of Science Editors.

Burrough-Boenisch, J. (2013). Defining and describing editing. In V. Matarese (Ed.), Supporting Research Writing: Roles and Challenges in Multilingual Settings (pp. 141-155). Oxford, UK: Chandos. https://doi.org/10.1016/B978-1-84334-666-1.50009-6

Bush, M. L., \& Henderson, D. (2003). Effective methods of teaching business education in the 21st century. In M. H. Rader (Ed.), National Business Education Association Yearbook (pp. 93-114). Reston, VA: National Business Education Association.

D'Aloisio, A. (2006). Motivating students through awareness of the natural correlation between college learning and corporate work settings. College Teaching, 54, 225-229. https://doi.org/10.3200/CTCH.54.2.225-230 


\section{Macrothink}

International Journal of Linguistics

ISSN 1948-5425

2019, Vol. 11, No. 5

Flowerdew, J. (1999). Problems in writing for scholarly publication in English: The case of

Hong Kong. Journal of Second Language Writing, 8, 123-145. https://doi.org/10.1016/S1060-3743(99)80116-7

Flowerdew, J., \& Wang, S. H. (2016). Author's editor revisions to manuscripts published in international journals. Journal of Second Language Writing, 32, 39-52. https://doi.org/10.1016/j.jslw.2016.03.004

Harwood, N. (2018). What do proofreaders of student writing do to a poorly written master's essay? Differing interventions, worrying findings. Written Communication, 35, 474-530.

Harwood, N., Austin, L., \& Macaulay, R. (2009). Proofreading in a UK university: Proofreaders' beliefs, practices, and experiences. Journal of Second Language Writing, 18, 166-190.

Horowitz, D. (1991). ESL writing assessments: Contradictions and resolutions. In L. Hamp-Lyons (Ed.), Assessing Second Language Writing in Academic Contexts (pp. 71-85). Norwood, NJ: Ablex.

Hiep, P. H. (2011). Good proofreaders / bad proofreaders. Translation Journal, 15(4).

Institute of International Education. (2014). Project Atlas: Trends and Global Data 2014. Retrieved from http://www.iie.org/Research-and-Publications/Project-Atlas

Kruger, H., \& Bevan-Dye, A. (2010). Guidelines for the editing of dissertations and theses: a survey of ditors' perceptions. Southern African Linguistics and Applied Language Studies, 28, 153-169. https://doi.org/10.2989/16073614.2010.519110

Lillis, T. M., \& Curry, M. J. (2006). Professional academic writing by multilingual scholars: Interactions with literacy brokers in the production of English-medium texts. Written Communication, 23, 3-35. https://doi.org/10.1177/0741088305283754

Lines, L. (2016). Substantive editing as a form of plagiarism among postgraduate students in Australia. Assessment \& Evaluation in Higher Education, 41, 368-383. https://doi.org/10.1080/02602938.2015.1013919

Luo, N., \& Hyland, K. (2016). Chinese academics writing for publication: English teachers as text mediators. Journal of Second Language Writing, 33, 43-55. https://doi.org/10.1016/j.jslw.2016.06.005

Marchall, C., \& Rossman, B. G. (1999). Designing Qualitative Research. Thousand Oaks: Sage Publication.

Mauranen, A. (1997). Hedging in language revisers' hands. In R. Markkanen, \& H. Schro“der (Eds.), Hedging and Discourse: Approaches to the Analysis of a Pragmatic Phenomenon in Academic Texts (pp. 115-133). Berlin: Walter de Gruyter. https://doi.org/10.1515/9783110807332.115

Miles, M. B., \& Huberman, A. M. (1994). Qualitative Data Analysis: An Expanded Sourcebook (2nd ed.). Thousand Oaks: Sage Publication.

Popken, R. (1989). Essay exams and papers: A contextual comparison. Journal of Teaching Writing, 8, 51-65. 


\section{Macrothink}

International Journal of Linguistics

ISSN 1948-5425

2019, Vol. 11, No. 5

Rebuck, M. (2014). Feedback on feedback: An analysis of L2 writers' evaluations of proofreaders. NU Ideas Journal, 3, 1-22.

Reid, J. (1994). Responding to ESL students' texts: The myths of appropriation. TESOL Quarterly, 28, 273-292. https://doi.org/10.2307/3587434 273-292.

Reid, J., \& Kroll, B. (1995). Designing and Assessing Effective Classroom Writing Assignments for NES and ES1 Students. Journal of Second Language Writing, 4, 17-41. https://doi.org/10.1016/1060-3743(95)90021-7

Rubin, H., \& Rubin, I. (1995). Qualitative Interviewing: The Art of Hearing Data. Thousand Oaks. Sage Publication.

Salter-Dvorak, H. (2019). Proofreading: How de facto language policies create social inequality for L2 master's students in UK universities. Journal of English for Academic Purposes, 39, 119-131. https://doi.org/10.1016/j.jeap.2019.03.004

Scurr, R. (2006, December 15). It is not enough to read an essay and mark it; one must also guess if a student has purchased professional help. The Times Higher Education Supplement, p. 13.

Turner, J. (2010). Supporting Academic Literacy: Issues of Proofreading and Language Proficiency. In G. Blue (Ed.), Developing Academic Literacy (pp. 39-51). Bern: Peter Lang.

\section{Appendix}

Questions for the interviews (In italics are the questions that the researcher generated, and the rest are the borrowed questions from Harwood et al.' study [2009].)

\begin{tabular}{ll}
\hline CATEGORY & QUESTIONS \\
\hline & -What skills do you think a proofreader should possess? \\
& -What experience do you think is useful? Why? \\
& -Could you tell me something about your own academic background and qualifications? \\
& -Cork? \\
& -Could you tell me about your own experience of writing within a formal or academic context? \\
& -Could you tell me about what you like most and least about proofreading? Why? \\
& -What texts have you worked on? \\
& -What texts would you be (un)willing to work on? \\
& -Where do you advertise for your proofreading services? (The place the interviewees advertise for their \\
proofreading services might lead to the types of texts that the proofreaders expect to receive to \\
proofread)
\end{tabular}


-When calculating a fee, what factors do you take into account?

-Do you have a notional rate/fee (e.g., price per page or hourly rate)?

-Do you prefer to see a piece of work before determining a rate/fee? Why/could you say more about that?

-Do you ever feel the need to alter your rate/fee once you've
-For what reason(s) have you proofread other people's texts?

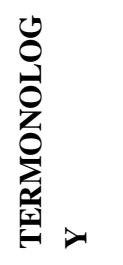

-What term or terms do you think best describes the service you provide? Why this term in particular? -What term or terms are generally used by the students who seek your help? Why do you think they prefer this term?

-What do you explain to a student during your preliminary discussion (e.g., the scope of your help; the time frame)?

-What do you tell students about the kind of service you offer?

-What sort of issues would you consider it appropriate to address in a student's text?

-Do you ever have doubts as to what kind of help you should give? For example, do you think there are some gray areas where you are uncertain whether to intervene, help, advise or not?

-Do you find that ethical issues ever arise (concerning the type of help that students seek from you?)

-Which of the following are you likely check and which are you not likely check

(page numbers, spelling, words, chapter titles, table of the contents, page layout):

-Are there any circumstances in which you would decline to [correct] a text?

-What is the difference between proofreading for a NS student and for an NNS student?

-Do you find out how well the essay did? Why(not)?
-Do you meet up with the student when returning their work, or once they've received their text back?
-Do you ever obtain a copy of markers' comments? Why(not)?
-How do you evaluate your success in proofreading?

-How would you note the error (e.g., edit, comment in margin, or discuss in person)?

-Do you ever indicate the location and type of errors rather than correct them?

\section{Copyrights}

Copyright for this article is retained by the author(s), with first publication rights granted to the journal.

This is an open-access article distributed under the terms and conditions of the Creative Commons Attribution license (http://creativecommons.org/licenses/by/4.0/) 